\title{
Characterization of SE1, a New General Transducing Phage of Salmonella typhimurium
}

\author{
By MONTSERRAT LLAGOSTERA, * JORGE BARBÉ AND \\ RICARDO GUERRERO \\ Department of Microbiology and Institute for Fundamental Biology, Autonomous University of \\ Barcelona, Bellaterra (Barcelona), Spain
}

(Received 25 July 1985; revised 23 September 1985)

\begin{abstract}
A transducing phage, SEl, which is able to infect Salmonella typhimurium was isolated from a Salmonella enteritidis strain. SEl is a temperate phage which is heteroimmune with respect to phages P22, L, KB1 and ES18. It is similar in morphology and size to phages P22, L and KB1 and is serologically related to phages $\mathrm{P} 22$ and L but not to KB1. Efficiencies of generalized transduction effected by phage SEl are similar to those for P22HT (int7), a mutant which mediates a high frequency of chromosomal gene transduction. The lengths of chromosomal DNA transduced by SE1 and P22HT (int 7) are similar. Furthermore, the SE1 prophage does not exclude the transducing particles from cells it has lysogenized; consequently it is possible to use both SE1 lysogens and non-lysogenic strains as recipients in SEl-mediated transduction experiments, and obtain similar transduction efficiencies. However, the SE1 prophage gives rise to a lysogenic conversion that decreases the rate of adsorption of SEl and $L$ phages by about $50 \%$, but does not affect adsorption of P22. Altogether these results suggest that phage SE1 may be a useful tool in the genetic manipulation of $S$. typhimurium.
\end{abstract}

\section{INTRODUCTION}

The most useful transducing vector in Salmonella typhimurium is bacteriophage P22, particularly its mutants which display high transduction frequencies. Other generalizedtransducing phages such as L (Bezdek \& Amati, 1967), KB1 (Boro \& Brenchley, 1971) and ES18 (Kuo \& Stocker, 1970) have also been reported for Salmonella.

Two phenomena modify the efficiency of P22-mediated transduction when the recipients are lysogenic for P22. First, it has been reported that lysogenic conversion by P22 produces a decrease in the adsorption rate of P22 (Zinder, 1958), due to modification of the P22 receptor site by glycosylation of the LPS of $S$. typhimurium (Lindberg, 1973). As a result, there is a slow decrease in the efficiency of P22-mediated transduction. Secondly, P22 has two superinfection exclusion systems. The first, sieB, excludes heteroimmune phages (Susskind et al., 1974b), while the second, sie $A$, is a nonspecific system that excludes many phages, including MG178, L and even P22 (Susskind et al., 1974a). The sieA system is also responsible for the exclusion of generalized-transducing particles generated by P22 (Ebel-Tsipis \& Botstein, 1971) or other phages. As a consequence, a large decrease in the transduction efficiency is observed (EbelTsipis \& Botstein, 1971; Susskind et al., 1971).

Susskind et al. $(1974 a)$ have proposed that the sieA exclusion system is a special DNA modification and/or restriction system that acts only on injected DNA, and which also interferes with the classical host restriction system. Thus, both superinfecting, active transducing particles and P22 phages would be able to adsorb normally and inject their DNA, which would then be partially degraded by the sie $A$ exclusion system.

In this paper we describe a general transducing phage of $S$. typhimurium, called SE1, which does not express a superinfection exclusion system that adversely affects the efficiency of SEl- 
mediated transduction. The physiological and morphological characteristics of SE1 are similar to those of phage P22 and phage L, which is serologically related to phage P22. The transducing properties of SE1 are discussed with reference to those of P22.

\section{METHODS}

Bacterial and bacteriophage strains. These are shown in Table 1. Strains lysogenic for SEl were picked from the centre of the growth in phage plaques, purified by repeated streaking and assayed for the presence of the SE1 prophage.

Media. LB broth, LB agar (Miller, 1972) and soft agar were used for growth of bacterial and bacteriophage strains and for titration of phages. Minimal medium AB (Clark \& Maaløe, 1967) supplemented with glucose $(0 \cdot 2 \%, \mathrm{w} / \mathrm{v})$ and required amino acids $\left(20 \mu \mathrm{g} \mathrm{ml}^{-1}\right)$ was used for transduction experiments. The components of the rich medium were obtained from Difco, the agar from Oxoid and the salts and the amino acids from Sigma.

Isolation of the phage and preparation of lysates. Phage SEl was obtained from a strain of Salmonella enteritidis isolated from a hospital patient. The strain was grown in $\mathrm{LB}$ broth at $37^{\circ} \mathrm{C}$. The culture was then centrifuged and the supernatant assayed for phage with $S$. typhimurium LT2 as indicator.

Phage lysates were routinely obtained by incubating a mixture of $S$. typhimurium LT2 and the desired phage at $37^{\circ} \mathrm{C}$ with aeration. Phages were added at an m.o.i. of 1 p.f.u. per c.f.u. Lysates were maintained over chloroform. Titres of up to $10^{10}$ p.f.u. $\mathrm{ml}^{-1}$ were usually obtained by this method.

When necessary, lysates were concentrated and partially purified by repeated centrifugation at $40000 \mathrm{~g}$, followed by resuspension of the pellets in phage buffer (Clowes \& Hayes, 1968).

One-step growth curve and Doermann experiment. These experiments were done as described by Clowes \& Hayes (1968), except that cells were lysed with chloroform.

Phage antisera. To obtain specific antisera against phages SE1, L, P22 and KB1, $100 \mathrm{ml}$ crude phage lysate was concentrated by high-speed centrifugation and the pellets resuspended in $10 \mathrm{ml} 0.4 \mathrm{M}-\mathrm{NaCl}$. Samples $(1 \mathrm{ml})$ of these suspensions were emulsified with $1 \mathrm{ml}$ Freund 's incomplete adjuvant (Sigma), and the mixtures were used to

Table 1. Bacterial and bacteriophage strains

\begin{tabular}{|c|c|c|}
\hline Strain & Phenotype & Source* \\
\hline $\begin{array}{l}\text { S. enteritidis } \\
\text { NA2673 } \\
\text { S. typhimuriu }\end{array}$ & $\mathrm{Amp}^{R} \mathrm{Carb}^{R} \mathrm{Clm}^{R}$ Tet $^{R}$, lysogenic for SE1 & G. Prats \\
\hline LT2 & Wild-type & J. L. Ingraham \\
\hline UA 1260 & LT2 but lysogenic for SE1 & This work \\
\hline UA 1020 & Rough & \\
\hline UA 1120 & Semirough & \\
\hline UA 1160 & LT2 Lys- & \\
\hline UA1180 & LT2 Leu- $^{-}$ & This laboratory \\
\hline UA 1201 & LT2 Thy- & \\
\hline UA1219 & LT2 Trp- & \\
\hline UA1190 & LT2 $\mathrm{Thr}^{-}$ & \\
\hline UAl197 & As UAl190 but lysogenic for P22 & \\
\hline UA1192 & As UA1190 but lysogenic for P22 sieA & This work \\
\hline UAl193 & As UA1190 but lysogenic for SEI & \\
\hline UA1010 & LT2 His $^{-}$Met $^{-}$ & This laboratory \\
\hline UA1121 & As UA1010 but lysogenic for P22 & \\
\hline UA1122 & As UA1010 but lysogenic for $\mathrm{P} 22$ sie $A$ & \\
\hline UAl123 & As UA1010 but lysogenic for SEI & This work \\
\hline UA 1124 & As UAll 23 but $\mathrm{His}^{+}$ & \\
\hline UA1125 & As UAl124 but $\mathrm{Met}^{+}$ & \\
\hline \multicolumn{3}{|l|}{ Phage } \\
\hline ES18 & Wild-type & J. R. Roth \\
\hline KBI & Wild-type & J. L. Ingraham \\
\hline L & Wild-type & J. Casadesús \\
\hline & Wild-type & J. R. Roth \\
\hline $\mathrm{P} 22 \mathrm{HT}$ int 7 & Int ${ }^{-}$, high transduction efficiency & J. L. Ingraham \\
\hline P22 sieA & SieA- & J. Casadesús \\
\hline & Wild-type & \\
\hline
\end{tabular}

*Addresses: G. Prats, Hospital de Sant Pau, Barcelona, Spain; J. L. Ingrahams, University of California, USA; J. R. Roth, University of Utah, USA; J. Casadesús, University of Sevilla, Spain. 
immunize rabbits by two intramuscular injections of $0.5 \mathrm{ml}$ (Hudson \& Hay, 1978). The rate of inactivation of phages P22, L, KBl and SEl by antisera raised against these phages was determined by the procedure of Adams (1959).

Density gradient centrifugation. $\mathrm{CsCl}$ gradients were prepared by resuspending the phage, after purification by high-speed centrifugation, in $4.0 \mathrm{M}-\mathrm{CsCl}, 10 \mathrm{mM}-\mathrm{MgSO}_{4}, 10 \mathrm{mM}-\mathrm{Tr}$ is $(\mathrm{pH} 8)$ and $0.1 \mathrm{mM}-\mathrm{Na}_{2}$ EDTA in a $13 \times$ $51 \mathrm{~mm}$ Beckman cellulose nitrate centrifuge tube (Davis et al., 1980). After centrifugation at 34500 r.p.m. at $20^{\circ} \mathrm{C}$ for $16 \mathrm{~h}$ in a Beckman $80 \mathrm{Ti}$ rotor, fractions were collected from the bottom of the gradient. Each fraction was assayed for $A_{260}, \mathrm{CsCl}$ density and phage titre. The different phages in a mixture were identified by titration against bacterial strains lysogenized with each one of them and against a P22 sie $A$ mutant.

Electron microscopy. Crude phage lysates were concentrated by high speed centrifugation and purified by $\mathrm{CsCl}$ gradient centrifugation. A drop of phage suspension was negatively stained with uranyl acetate on carbon-coated copper grids for electron microscopy (Dawes, 1971). Excess liquid was removed with filter paper and the grids were allowed to dry in air. The preparations were examined and photographed in a Hitachi electron microscope at 20000-60000 magnification.

Transduction procedure. Recipient cells for transduction were grown at $37^{\circ} \mathrm{C}$ in LB broth $(20 \mathrm{ml})$ inoculated with a $24 \mathrm{~h}$ culture of bacteria to give a cell density of about $2 \times 10^{8} \mathrm{c}$.f.u. $\mathrm{ml}^{-1}$. Phage were usually grown in $S$. typhimurium LT2 as propagation strain. Mixtures $(1: 1)$ containing one phage per recipient bacterium were incubated for $30 \mathrm{~min}$ at $37^{\circ} \mathrm{C}$ in aerobic and static tubes of LB broth. Samples of the mixtures $(0.1 \mathrm{ml})$ were plated on minimal salts medium with glucose $(0.2 \%, \mathrm{w} / \mathrm{v})$ and supplements when appropiate, and incubated at $37^{\circ} \mathrm{C}$ for $48 \mathrm{~h}$ (Ebel-Tsipis \& Botstein, 1971). Controls for spontaneous reversion were made simultaneously, and samples were plated to determine the number of p.f.u. and c.f.u. in the mixtures. Transduction frequencies are given as T/P ratios, i.e. the ratio of the number of recombinant transductants to the number of p.f.u.

Determination of phage adsorption rates. Adsorption rates were determined by measuring the unadsorbed phages (Adams, 1959). Exponential bacterial cultures were infected at an m.o.i. of $0 \cdot 1$ p.f.u. per c.f.u. and kept at $37^{\circ} \mathrm{C}$ without shaking. Samples were periodically withdrawn and treated with chloroform. When the bacterial strains were lysogenic, a control for spontaneous phage induction was made simultaneously and the result was taken into consideration in the calculations.

\section{RESULTS AND DISCUSSION}

\section{General characterization of phage SE1}

Morphological and physical characteristics and growth kinetics of phage SEl were studied and compared with those of several phages previously described in $S$. typhimurium. The mature SEl virion was a hexagonal particle of $60 \mathrm{~nm}$ diameter, with a short base plate of $12 \mathrm{~nm}$ which showed six-fold symmetry (Fig. 1). This morphology is similar to that of phages P22 (Susskind \& Botstein, 1978), L (Bezdek \& Amati, 1967) and KB1 (Brenchley, 1971). Nevertheless, SE1 was heteroimmune with respect to phages $\mathrm{P} 22, \mathrm{~L}, \mathrm{~KB} 1$ and ES1 8 because it was able to grow on cells lysogenic for these phages (data not shown).

Phage SE1 had the same buoyant density as phage P22, which was higher than that of phage $\mathrm{L}$ (Fig. 2). The density values obtained for phages $\mathrm{L}\left(1.505 \mathrm{~g} \mathrm{~cm}^{-3}\right)$ and $P 22\left(1.515 \mathrm{~g} \mathrm{~cm}^{-3}\right)$ were in accordance with the values reported by Bezdek \& Amati (1967).

The one-step growth and Doermann experiments with phage SE1 showed similar growth kinetics to those reported for phages P22 (Grabnar \& Hartman, 1968) and L (data not shown). The minimal latent period for phage SE1 was $42 \mathrm{~min}$, while that for phage P22 under the same conditions was $36 \mathrm{~min}$, in agreement with the data reported by Grabnar \& Hartman (1968). However, the burst size of SEl was about 300 p.f.u. per infected bacterium, three times the value obtained for phages P22 and L.

\section{Antigenic properties}

Table 2 presents the $K$ values obtained in cross-serological tests between phages P22, L, SE1 and $\mathrm{KB} 1$ and their respective antisera. For comparison, the $K$ values are expressed as percentages, where 100 indicates the inactivation by an anti-phage serum against the same phage.

Anti-P22 serum inhibited the plaque-forming ability of phages L and SE1 (Table 2), but it had a more inhibitory effect on phage $L$ than on phage SE1. Similarly, the anti-L serum and the anti- 


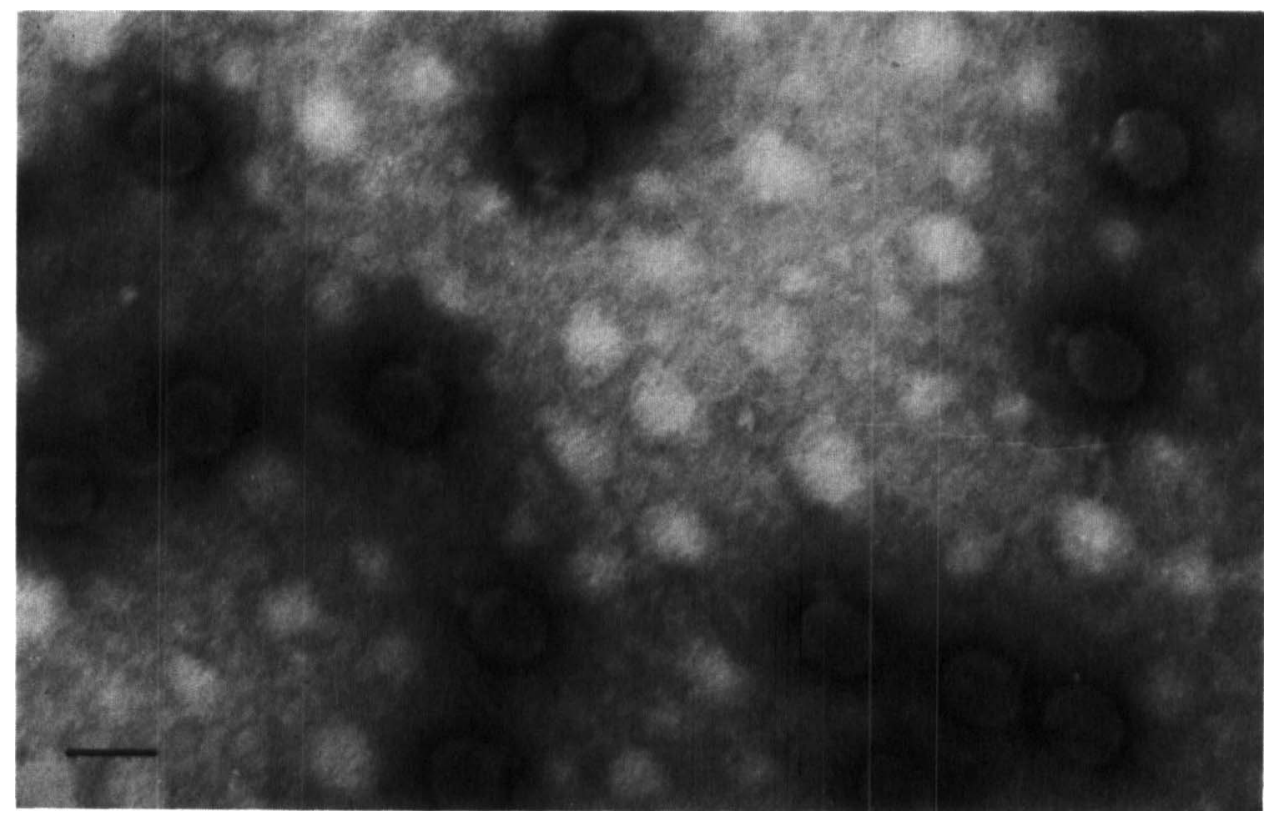

Fig. 1. Electron micrograph of phage SEl. Bar, $75 \mathrm{~nm}$.



Fig. 2. Phage titre after $\mathrm{CsCl}$ density gradient centrifugation of phages $\mathrm{P} 22(\boldsymbol{\nabla}), \mathrm{L}(\bullet)$ and $\mathrm{SEl}(\square)$. The $\mathrm{CsCl}$ density gradient is also shown $(\mathrm{O})$.

SE1 serum reacted with phage $\mathrm{P} 22$ with different efficiencies. Phages $\mathrm{SE} 1$ and $\mathrm{L}$ were shown to be serologically related, because the anti-L and anti-SEl serum inhibited the plaque-forming ability of phages SEl and $L$ respectively (Table 2 ).

As a control, cross-reactions with phages $\mathrm{P} 22$ and $\mathrm{KB} 1$ were tested. In agreement with previous data (Brenchley, 1971), the results indicated that phages P22 and KB1 were not related. Furthermore, analogous results were obtained with both anti-SE1 and anti-L sera with respect to phage $\mathrm{KB} 1$, showing that phages $\mathrm{SE} 1$ and $\mathrm{L}$ were not serologically related to $\mathrm{KB} 1$. 
Table 2. Cross-serological tests between phages P22, L, SE1 and KB1

\begin{tabular}{lrrrr} 
& \multicolumn{4}{c}{ Percentage $K$ value* } \\
\cline { 2 - 5 } antiserum & P22 & \multicolumn{1}{c}{ Phage } & SE1 & KB1 \\
P22 & 100 & 55 & 38 & 0 \\
L & 79 & 100 & 50 & 0 \\
SE1 & 34 & 55 & 100 & 0 \\
KB1 & 0 & 0 & 0 & 100
\end{tabular}

* The $K$ values for the reaction between each phage and its own antiserum were $55 \mathrm{~min}^{-1}$ for $\mathrm{P} 22,67 \mathrm{~min}^{-1}$ for $\mathrm{SE} 1,84 \mathrm{~min}^{-1}$ for $\mathrm{L}$ and $26.5 \mathrm{~min}^{-1}$ for $\mathrm{KBl}$.

Table 3. Adsorption constants of phages SEI, $L$ and P22 on SE1 lysogenic and non-lysogenic $S$. typhimurium strains

$\begin{array}{lll}\text { Bacteriophage } & \overbrace{\text { LT2 }}^{K\left(\mathrm{ml} \mathrm{c.f.u.}^{-1} \mathrm{~min}^{-1}\right)} \\ \text { SE1 } & 1.6 \times 10^{-9} & \text { UA1260 } \\ \text { L } & 7.5 \times 10^{-10} & 1.8 \times 10^{-10} \\ \text { P22 } & 4.9 \times 10^{-11} & 4.3 \times 10^{-9}\end{array}$

\section{Adsorption rate}

Phage SE1 probably adsorbs to LPS, since it was unable to infect either semirough or rough mutants of $S$. typhimurium strains (data not shown).

Table 3 shows the adsorption constants of phage SE1 on both an SE1 lysogen (UA1260, a derivative of LT2) and non-lysogenic strain LT2. The SE1 prophage affected the adsorption rate of phage SE1, giving a lower adsorption constant on the lysogenic strain UA1260 than on the non-lysogenic strain LT2. A similar effect was observed in the adsorption constants of phage L, which were lower on the SE1 lysogen than on the non-lysogenic strain. However, the SE1 prophage did not affect the adsorption rate of P22 (Table 3), suggesting that phages P22 and SE1 have different $S$. typhimurium receptor sites.

These results suggest that the SE1 prophage causes a lysogenic conversion, similar to that reported for phage P22 (Gough \& Scott, 1972), which is due to the presence of a new antigen (factor 1), encoded by the prophage, on the surface of $S$. typhimurium. The lysogenic conversion produced a twofold decrease in the rate of SE1 adsorption. A similar effect was seen for the rate of $\mathrm{L}$ adsorption. Further studies are necessary to establish the connection between phages SEl and $\mathrm{L}$ and also to determine the basis of the modification to the surface of $S$. typhimurium, and probably $S$. enteritidis.

\section{Transduction test}

Preliminary results from transduction tests with phage SEl showed that it can accomplish generalized transduction in $S$. typhimurium. Results from cotransduction tests with SEl and P22HT (int7) showed that these phages can transport the same length of bacterial DNA in their virions, since they gave the same cotransduction frequency for thy and lys markers $(40 \%)$. Schmieger \& Backhaus (1973) have shown that P22 can carry $26 \times 10^{6}$ to $27 \times 10^{6} \mathrm{Da}$, which represent about 1/100 of the total Salmonella chromosome (Sanderson \& Hartman, 1978).

Table 4 shows the results obtained for transduction of various markers by phages SE1 and P22HT (int7) at an m.o.i. of 1. The results indicated that both phages had similar transduction frequencies with non-lysogenic recipients and that the transduction efficiency of phage SE1 depended on which marker was transduced. A similar phenomenon has also been reported for phage P22 and has been attributed to the fact that bacterial DNA contains pac or pac-like sequences which can be recognized by the phage-packaging complex as a signal to start a series 
Table 4. Transduction frequency of various markers by phages SEl and P22HT (int7)

$\begin{array}{lccc}\text { Marker } & \text { Position* } & \overbrace{\text { P22HT (int7) }}^{\text {Transduction frequency }} \\ \text { leu } & 2 & 2.8 \times 10^{-6} & \text { SE1 } \\ \text { met } & 87 & 3.5 \times 10^{-5} & 7.6 \times 10^{-6} \\ \text { his } & 42 & 1.5 \times 10^{-4} & 5.5 \times 10^{-6} \\ \text { thr } & 0 & 1.8 \times 10^{-5} & 8.1 \times 10^{-6} \\ \text { thy } & 61 & 9.3 \times 10^{-7} & 2.6 \times 10^{-7} \\ \text { trp } & 34 & 6.4 \times 10^{-6} & 3.6 \times 10^{-6}\end{array}$

* Map position according to Sanderson \& Roth (1983).

$\dagger$ No. of recombinant transductants/no. of p.f.u.

Table 5. Transduction frequency of phages SEl and P22HT (int7) on lysogenic and nonlysogenic strains

\begin{tabular}{lccc} 
Marker & $\begin{array}{l}\text { Prophage in } \\
\text { recipient cell }\end{array}$ & $\overbrace{\text { P22HT (int7) }}^{\text {Transduction frequency* }}$ & SE1 \\
$h i s$ & - & $1.5 \times 10^{-4}$ & $5.5 \times 10^{-6}$ \\
$h i s$ & SE1 & $2.3 \times 10^{-4}$ & $1.2 \times 10^{-6}$ \\
$h i s$ & $\mathrm{P} 22$ & $3.6 \times 10^{-6}$ & \\
$h i s$ & $\mathrm{P} 22$ sieA & $4.9 \times 10^{-5}$ & \\
$m e t$ & - & $3.5 \times 10^{-5}$ & $7.9 \times 10^{-5}$ \\
$m e t$ & $\mathrm{SE} 1$ & $4.0 \times 10^{-5}$ & $2.2 \times 10^{-5}$ \\
$m e t$ & $\mathrm{P} 22$ & $5.9 \times 10^{-7}$ & \\
$m e t$ & $\mathrm{P} 22$ sieA & $1.4 \times 10^{-5}$ & \\
$t h r$ & - & $1.9 \times 10^{-5}$ & $8.1 \times 10^{-6}$ \\
$t h r$ & $\mathrm{SE} 1$ & $1.3 \times 10^{-5}$ & $1.5 \times 10^{-6}$ \\
$t h r$ & $\mathrm{P} 22$ & $1.0 \times 10^{-7}$ & \\
$t h r$ & P22 sieA & $5.2 \times 10^{-6}$ & \\
\multicolumn{4}{c}{ * No. of recombinant transductants/no. of p.f.u. }
\end{tabular}

of sequential packaging events (Schmieger, 1982). Thus, for a given chromosomal marker, the probability of being encapsulated depends on its distance from a pac signal.

A sie $A$ superinfection exclusion system that excludes transducing particles has been described in phage P22 (Susskind et al., 1974a). In recipients lysogenic for P22 this system effects a marked decrease, which is marker-dependent, in the transduction efficiency of P22 (Ebel-Tsipis \& Botstein, 1971). To study this phenomenon in phage SE1, transduction experiments with SE1 and P22HT (int7), using SEl lysogens and non-lysogenic strains as recipients, were done. Transductions with $\mathrm{P} 22 \mathrm{HT}$ ( int 7), using recipients lysogenic for $\mathrm{P} 22$ and $\mathrm{P} 22$ sie $A$, were done as controls.

It can be seen that the SE1 transduction frequencies decreased by only about four- to fivefold when the recipient was an SEl lysogen (Table 5). On the other hand, the transduction frequencies of P22HT (int7) decreased significantly when the cells were P22 lysogens. However, when the recipient was a P22 sieA lysogen the decrease was only about fourfold. These results confirmed the operation of the sieA system in the transduction experiments with P22 and P22 lysogens. In addition, they suggested that phage $\mathrm{SE} 1$ does not encode a superinfection exclusion system similar to sie $A$ of $\mathrm{P} 22$.

Although the SE1 prophage produced a decrease in the transduction efficiency of phage SE1, it did not lower the efficiency of transduction mediated by P22. The P22 sieA prophage caused a decrease in the P22HT (int 7) transduction efficiencies. Both phenomena are similar and can be attributed to the decrease in the rate of SE1 adsorption (Table 3) on SE1 lysogens and the lysogenic conversion of the P22 prophage respectively. 
These results indicated that it is possible to use SE1 lysogens as recipients in phage SE1mediated, successive transductions. To test this possibility we performed transduction experiments, at an m.o.i. of 1 , with UA1123 as recipient, selecting first for the phenotype $\mathrm{His}^{+}$. One such $\mathrm{His}^{+}$transductant was isolated and used as a recipient in a second SE1 transduction experiment, selecting for $\mathrm{Met}^{+}$. The efficiencies of transduction obtained were similar to those obtained using phage SE1 as a transducing vector and an SE1 lysogen as recipient (Table 5).

We have shown that phage SE1 is able efficiently to mediate successful transduction to an SE1 lysogen and so we propose that it may be a useful tool in genetic studies of $S$. typhimurium, mainly when the transduction frequency of phage $\mathrm{P} 22$ is greatly decreased by the sie $A$ exclusion system of the P22 prophage.

We are indebted to Dr Guillem Prats for providing S. enteritidis NA2673. We also thank Drs J. L. Ingraham, J. R. Roth and J. Casadesús for their generous gift of several strains. We acknowledge the help of the Comissio Interdepartamental de Recerca i Innovació Tecnologica of the Generalitat de Catalunya for a grant for the purchase of equipment. This work was partially supported by a grant of the Comisión Asesora de Investigación Cientifica y Técnica, Spain.

\section{REFERENCES}

ADAMS, M. H. (1959), Bacteriophages. New York: Interscience.

BezdeK, M. \& Amati, P. (1967). Properties of P22 and a related Salmonella typhimurium phage. I. General features and host specificity. Virology 31, 272-278.

BoRo, H. \& BRENCHLEY, J. E. (1971). A new generalized transducing phage for Salmonella typhimurium LT2. Virology 45, 835-836.

Clark, D. J. \& MaAløe, O. (1967). DNA replication and the division cycle in Escherichia coli. Journal of Molecular Biology 23, 99-112.

Clowes, R. C. \& HAYES, W. (1968). Experiments in Microbial Genetics. Oxford: Blackwell Scientific Publications.

Davis, R. W., Botstein, D. \& Roth, J. R. (1980). Advanced Bacterial Genetics. Cold Spring Harbor, NY: Cold Spring Harbor Laboratory.

DAwES, C. J. (1971). Biological Techniques in Electron Microscopy. New York: Barnes \& Noble, Inc.

Ebel-Tsipis, J. \& Botstein, D. (1971). Superinfection exclusion by $\mathrm{P} 22$ prophage in lysogens of Salmonella typhimurium. I. Exclusion of generalized transducing particles. Virology 45, 629-637.

Gough, M. \& ScoTT, J. V. (1972). Location of the prophage conversion gene of P22. Virology 50, 603605.

Grabnar, M. \& Hartman, P. E. (1968). MG40 phage, a transducing phage related to $\mathrm{P} 22$. Virology 34, 521530.

Hudson, L. \& Hay, F. C. (1978). Practical Immunology. Oxford: Blackwell Scientific Publications.

Kuo, T. \& STOCKer, B. A. D. (1970). ES18, a general transducing phage for smooth and nonsmooth Salmonella typhimurium. Virology 42, 621-632.

LINDBERG, A. A. (1973). Bacteriophage receptors. Annual Review of Microbiology 27, 205-241.
MILlER, J. M. (1972). Experiments in Molecular Genetics. Cold Spring Harbor, NY: Cold Spring Harbor Laboratory.

Sanderson, K. E. \& Hartman, P. E. (1978). Linkage map of Salmonella typhimurium. Edition V. Microbiological Reviews 42, 471-519.

SANDERSon, K. E. \& Roth, J. R. (1983). Linkage map of Salmonella typhimurium. Edition VI. Microbiological Reviews 47, 410-553.

SCHMIEGER, H. (1982). Packaging signals for phage P22 on the chromosome of Salmonella typhimurium. Molecular and General Genetics 187, 516-518.

SCHMIEGER, H. \& BACKHAUS, H. (1973). The origin of DNA in transducing particles in P22-mutants with increased transduction-frequencies (HT-mutants). Molecular and General Genetics 120, 181-190.

Susskind, M. M. \& BotsteIN, D. (1978). Molecular genetics of bacteriophage P22. Microbiological Reviews 42, 385-413.

Susskind, M. M., Wright, A. \& Botstein, D. (1971). Superinfection exclusion by $\mathrm{P} 22$ prophage in lysogens of Salmonella typhimurium. II. Genetic evidence for two exclusion systems. Virology 45, 638-652.

Susskind, M. M., BotsteIN, D. \& WRIGHT, A. (1974a). Superinfection exclusion by $\mathrm{P} 22$ prophage in lysogens of Salmonella typhimurium. III. Failure of superinfecting phage DNA to enter sie $A^{+}$lysogens. Virology 62, 350-366.

Susskind, M. M., WRIGHT, A. \& BotsteIN, D. (1974b). Superinfection exclusion by $\mathrm{P} 22$ prophage in lysogens of Salmonella typhimurium. IV. Genetics and physiology of sieB exclusion. Virology 62, 367-384.

ZINDER, N. D. (1958). Lysogenization and superinfection immunity in Salmonella. Virology 5, 291-326. 